\title{
A JUDICIALIZAÇÃO DO DIREITO INTERNACIONAL: A JURISDIÇÃO DA CORTE INTERNACIONAL DE JUSTIÇA SOB A ÓTICA DO VOLUNTARISMO ESTATAL NO CASO DO BRASIL
}

\section{THE JUDICIALIZATION OF THE INTERNATIONAL LAW: THE JURISDICTION OF THE INTERNATIONAL COURT OF JUSTICE UNDER THE STATE CONSENT CONCERNING BRAZIL}

\author{
${ }^{1}$ Laércio Dias Franco Neto \\ ${ }^{2}$ Cristina Figueiredo Terezo Ribeiro
}

\begin{abstract}
RESUMO
$\mathrm{O}$ artigo demonstra os fundamentos e a validade do Direito Internacional sob a perspectiva voluntarista do Estado, para ingressar no tema da judicialização das demandas de Direito Internacional como método de solução definitiva das controvérsias internacionais. A Corte Internacional de Justiça é o foro adequado para exercer essa função, porém, em razão de exercer jurisdição voluntária, carece de uma maior utilização dos seus serviços por uma resistência dos Estados de conferir ao Direito Internacional a solução de certas controvérsias, como é parcialmente o caso do Brasil. Essa escolha não representa negação ao Direito Internacional, mas enfraquece o seu desenvolvimento.
\end{abstract}

Palavras-chave: Corte internacional de justiça, Jurisdição, Voluntarismo estatal, Direito internacional

\begin{abstract}
The article demonstrates the foundations and the validity of the International Law under the State consent, to reach the subject of the judicialization of the demands in the International Law as a definitive solution to the international controversies. The International Court of Justice is the proper a forum to fulfill this task, but due to its voluntary jurisdiction, the Court lacks demands since States resist to give to International Law the final decision in certain areas, like Brasil, in most cases. This choice does not imply the refusal to recognize the International Law, but it threatens its development.
\end{abstract}

Keywords: International court of justice, Jurisdiction, State consent, International law

\footnotetext{
${ }^{1}$ Doutorando em Direito pela Universidade Federal do Pará, UFPA, Pará, PA. (Brasil). Professor na Faculdade Metropolitana da Amazônia, FAMAZ, Pará, PA.(Brasil). E-mail: laerciodfranco@gmail.com

${ }^{2}$ Professora e Doutora em Direito pela Universidade Federal do Pará - UFPA. (Brasil). E-mail: cfterezo@hotmail.com
} 


\section{INTRODUÇÃO}

Hodiernamente, atribuir a validade do Direito Internacional ao voluntarismo estatal é objeto de estudos que visam retirar essa faculdade dos Estados. Ainda que seja inegável a relativização dessa premissa, não se pode deixar de reconhecer que essa lógica ainda impera em muitas áreas do Direito Internacional, o que não é por si um problema. Afinal, não se pode negar a relação especial dos Estados com os próprios modos de produção das fontes.

Nesse sentido, reconhecer o voluntarismo estatal como requisito indispensável para a existência de algumas áreas do Direito Internacional é natural. Mais do que isso: as próprias áreas que estão mais objetivadas, como Direitos Humanos ou Comércio Internacional, iniciaram o seu desenvolvimento a partir de um ato voluntarista precursor.

No que concerne a questão da judicialização das demandas de Direito Internacional (que não envolvam Direitos Humanos, por exemplo), em especial no que diz respeito à Corte Internacional de Justiça, a tese do voluntarismo estatal ainda é a regra predominante. Portanto, visa-se observar em aspectos práticos se essa condição representa um problema para o Direito Internacional e quais seriam os argumentos para a não adoção de cláusulas de jurisdição obrigatória.

A aparente contradição dos Estados ao optar pela judicialização em temas como o Comércio Internacional, e ao mesmo tempo, resistir a jurisdição obrigatória da Corte Internacional de Justiça pode ser atribuída ainda a concepção majoritária dos agentes estatais de se valer da teoria voluntarista do Direito.

Logo, em razão da situação posta pela realidade dos fatos, abordar-se-á a questão da judicialização do Direito Internacional sob a ótica do voluntarismo estatal, inclusive analisando a posição brasileira nesse tema.

\section{FUNDAMENTO VOLUNTARISTA DO DIREITO INTERNACIONAL}

O Direito Internacional é considerado um ramo da Ciência Jurídica. No entanto, observa-se uma série de especificidades em relação às outras matérias do Direito Interno. Portanto, parece razoável estabelecer um paralelo entre esses ramos do Direito.

Uma maneira de caracterizar um sistema jurídico interno de virtualmente qualquer Estado soberano ocorre por meio da identificação de uma instituição ou um órgão competente para criar normas; Tribunais com instâncias hierárquicas capazes de resolver definitivamente quaisquer problemas oriundos das normas; e um poder central capaz de implementar, por meio da força, se necessário, as decisões legalmente constituídas. 
As normas que compõem um sistema jurídico podem ser primárias ou secundárias, sob uma perspectiva de vinculação do Direito a regras obrigatórias. As normas primárias são as que regulam propriamente a conduta, exigindo uma comissão ou omissão por partes dos agentes, enquanto as normas secundárias estariam sempre relacionadas a uma norma primária, estabelecendo de que modo elas podem ser determinadas de forma excludente, assim como a configuração de sua violação e das suas consequências.

Contudo, quando se observa o Direito Internacional, não se identifica concretamente nenhum desses elementos básicos que integram o Direito Interno. Não existe um órgão legislativo internacional, tampouco um Poder Judiciário com jurisdição compulsória e capaz de aplicar sanções em caso do descumprimento das suas decisões.

Em relação às normas, o sistema jurídico internacional só seria composto de normas primárias, inexistindo normas secundárias. Hebert Hart acrescenta que também falta “[...] uma norma de reconhecimento unificadora que especifique as 'fontes' do direito e forneça critérios gerais para a identificação de suas normas”. (2009, p. 277)

Em consequência das antinomias apresentadas entre Direito Interno e Direito Internacional, um questionamento de Malcolm Shaw se apresenta como preciso para essa discussão:

Assim, se não há instituição identificável para estabelecer regras ou mesmo para esclarecêlas, ou ainda para garantir que aqueles que as descumprem sejam punidos, como é possível chamar o direito internacional de direito? (2010, p. 3)

A expressão Direito Internacional foi pela primeira vez utilizada em 1780, tendo sido cunhada por Jeremy Bentham, que acabou por substituir a nomenclatura vigente à época, "Direito das Gentes". Não é o objetivo do presente trabalho discutir qual o melhor termo existente, mas é inegável que Direito Internacional está consagrado.

Justamente por conta da nomenclatura, a comparação entre Direito Internacional e Direito Interno se torna inevitável. Bentham defendeu a expressão Direito Internacional por considerar que ela é suficientemente análoga ao Direito Interno. (1996). Hart se pronuncia acerca do tema:

Em primeiro lugar, a analogia é de conteúdo, e não de forma; em segundo lugar, nessa analogia de conteúdo, nenhum outro tipo de norma social é tão semelhante ao direito interno quanto as normas do direito internacional. (2009, p. 306)

Um dos principais conflitos entre Direito Interno e Direito Internacional existe em razão da ausência de um poder central internacional capaz de emitir sanções organizadas, o que implicaria na ausência de poder vinculante do Direito Internacional e até mesmo na base do 
fundamento da indagação se seria esse ramo verdadeiramente Direito. Lafayete Rodrigues, jurista brasileiro do início do século XX, questionava-se:

Há quem pense que o direito internacional não seja senão um código de regras e máximas morais, a que as nações, na ausência de jurisdição superior incumbida de aplicá-lo e fazê-lo observar, só prestarão obediência quando seus interesses o permitirem ou o exigirem, ou quando lhes faltar poder para impunemente violá-lo. Não haverá nisso uma parcela, uma partícula de verdade? (1902)

No entanto, o reconhecimento dessa premissa significaria que o Direito seria essencialmente uma questão de ordens balizadas por ameaças. Hart defende o abandono dessa ideia, constatando que "não parece haver uma boa razão para limitar a ideia normativa de obrigação às normas apoiadas por sanções organizadas". (2009, p. 281).

É importante que se reconheça a total diferença de possibilidade de aplicação de uma sanção a uma pessoa e por outro lado, a um Estado. A natureza de ambos é totalmente diferente, podendo-se inferir que a base comparativa que se insiste em fazer seja desproporcional.

Logo, não se pode concluir que o Direito Internacional não seja vinculante em razão da ausência de mecanismos coercitivos em sua organização. Uma vez mais, recorre-se à Malcolm Shaw:

Já que não se pode descobrir a natureza do Direito Internacional com base em uma definição
de direito fundado em sanções, a característica da ordem internacional legal deve ser
examinada em busca de se revelar se de fato um Estado se considera compelido a obedecer
às regras do Direito Internacional, e se sim, o motivo. Se, de fato, a resposta para a primeira
questão for negativa, de que os Estados não precisam agir de acordo com ditas regras, então
não existe um sistema de Direito Internacional que mereça o nome. ${ }^{1}$ (2010, p.5). (tradução
nossa)

Não resta qualquer dúvida que Direito Internacional e Direito Interno, apesar da semelhança nas expressões, se referem de fato a fenômenos, ambos jurídicos, só que distintos.

No Direito Interno da maior parte dos Estados, a estrutura legal é hierárquica e vertical. Por outro lado, o sistema internacional é horizontal, formado por 193 Estados soberanamente reconhecidos ${ }^{2}$, dispondo de igualdade entre eles e sem qualquer ingerência direta de um sobre o outro, ao menos no aspecto teórico.

No Direito Interno, a pessoa está sujeita apenas a obedecer ou não a lei. No Direito Internacional, os Estados não apenas optam por obedecer ou não a lei, como também eles são

\footnotetext{
1 "Since one cannot discover the nature of international law by reference to a definition of law predicated upon sanctions, the character of the international legal order has to be examined in order to seek to discover whether in fact states feel obliged to obey the rules of international law and, if so, why. If, indeed, the answer to the first question is negative, that states do not feel the necessity to act in accordance with such rules, then there does not exist any system of international law worthy of the name"

${ }^{2}$ Números de Estados membros da Organização das Nações Unidas.
} 
diretamente responsáveis pela elaboração das normas internacionais por meios convencionais, na maioria dos casos.

Apesar da impressão inicial de que tal sistema atribuiria verdadeira discricionariedade aos Estados para a livre escolha de quando obedecer ou ignorar determinada legislação internacional, a maior parte das regras estabelecidas pelo Direito Internacional são adimplidas. (MORGENTHAU, 2003, p.290)

Qual seria o motivo para o respeito às regras do Direito Internacional?

A ausência de um sistema central de sanções não invalida a existência de outros meios coercitivos e de persuasão na ordem internacional, tais como a reciprocidade mediante os Estados pares, assim como vantagens advindas pelo respeito das regras do Direito Internacional. Ainda que não se possa concluir que esses fundamentos não são juridicamente exigíveis, no Direito Internacional, atribuir efetividade às suas normas requer muito mais do que simplesmente base jurídica, o que reputa importância para os conceitos de soft law. ${ }^{3}$

O melhor conceito para soft law parece ser de que se trata de normas internacionais, que apesar de excluídas do rol elencado pelo artigo 38, parágrafo $1^{\circ}$ do Estatuto da Corte Internacional de Justiça ou por não possuírem requisitos normativos capazes de criarem direitos e obrigações exigíveis, ainda assim são capazes de produzir alguns efeitos legais. (FRANCIONI, 2008, p. 168)

Parte da doutrina clássica ${ }^{4}$ reputa ao consenso, ao voluntarismo estatal a base legal de exigibilidade do Direito Internacional. O Estado não seria obrigado a se comprometer internacionalmente por uma questão de soberania, mas a partir do momento em que o faz, ficaria vinculado a respeitar o compromisso.

Seria o caso de aplicação do princípio pacta sunt servanda, previsto no artigo 26 da Convenção de Viena sobre Direito dos Tratados de $1969^{5}$, como fundamento para impedir Estados a descumprirem suas obrigações internacionais. Como citado, as fontes do Direito Internacional estão enunciadas, pelo aspecto formal, no Estatuto da Corte Internacional de Justiça, em seu artigo $38.1^{6}$.

\footnotetext{
${ }^{3}$ Termo cunhado pelo Lord Arnold Mcnair, primeiro presidente da Corte Europeia de Direitos Humanos.

${ }^{4}$ Autores como Malcolm Shaw e J.S Watson.

${ }^{5}$ Convenção sobre Direitos dos Tratados: Art. 26: Todo o tratado em vigor vincula as partes e deve ser por elas executado de boa-fé.

${ }^{6}$ Estatuto da CIJ: Art. 38.1: A Corte, cuja função seja decidir conforme o direito internacional as controvérsias que sejam submetidas, deverá aplicar;
} 
Ao mesmo tempo, é interessante o questionamento do que aconteceria se um Estado resolvesse abandonar todos seus compromissos internacionais, desobedecê-los simplesmente pelo argumento da falta de exigência do Direito Internacional.

Em uma análise empírica, é de se esperar que dito Estado torne-se um pária na sociedade internacional, não conseguindo constituir relações diplomáticas e comerciais com praticamente nenhum outro Estado, rumando a um consequente isolamento, dificultando a sua própria coexistência com os seus pares ${ }^{7}$.

A possibilidade de uma consequência como descrita acima demonstra uma necessidade indispensável de alguma relação entre os Estados e, por conseguinte, de respeito às regras existentes do Direito Internacional.

Uma crítica que se pode fazer ao desenvolvimento desse pensamento é a base política no mecanismo coercitivo ao Estado, e não estritamente jurídica. Contudo, a relação entre Política e Direito Internacional é muito diferente no âmbito do Direito Interno. Só é possível a compreensão do Direito Internacional se considerado os fatores políticos conjugados com os jurídicos. Dessa forma, Malcow Shaw preceitua que:

Está claro que nunca haverá uma completa separação entre o direito (internacional) e a política. Não importa a teoria do direito ou da filosofia política que seja professada, os laços inextricáveis entre direito (internacional) e política devem ser reconhecidos. (tradução nossa) (2010, p.11).

No sistema internacional, os Estados têm a faculdade de elaborar as normas em conjunto, assim como decidir pela sua aplicação. Apesar do princípio pacta sunt servanda ser uma disposição estatal em se comprometer com aquela convenção estipulada, eventual método para obrigar um Estado a adimpli-la pode ser considerado uma violação à soberania.

Por isso, as principais formas de coerção ao Estado não são jurídicas, nem baseadas na força, mas sim políticas ou quase-legais. Logo, faz parte do Direito Internacional reconhecer essas relações sem estrita vinculação jurídica como a regra em seu sistema.

Essa constatação pode funcionar para respaldar atuações proativas de órgãos administrativos internacionais, como também podem servir de meio de defesa para os Estados nacionais.

Em verdade, ao se identificar o único sistema internacional capaz de se utilizar da força para impor suas decisões, percebe-se que a influência política nas decisões do órgão é de tal modo que corrobora essa relação inextricável entre Política e Direito Internacional.

\footnotetext{
${ }^{7} \mathrm{O}$ exemplo concreto que mais se aproxima da situação descrita acima é o do Estado africano da Somália, considerado como um Estado falido pelas últimas duas décadas, sem conseguir estabelecer relações com a comunidade internacional.
} 
É o caso do Conselho de Segurança da ONU. Este é o único órgão capaz de aplicar sanções e garantir sua execução no sistema internacional, mesmo que se utilizando da força para implementá-la ${ }^{8}$.

No entanto, suas decisões dependem de uma maioria qualificada no Conselho, não sendo possível que algum membro permanente vote contra (critério do consenso).

Dessa maneira, torna-se evidente que mesmo no órgão que detém o monopólio do uso da força, o que se obedece não são parâmetros eminentemente jurídicos, mas um fundamento político que norteia cada caso a ser decidido.

O exemplo do Conselho de Segurança da ONU, além de reforçar a ligação entre Política e Direito Internacional, também serve para demonstrar que a soberania não é um direito absoluto.

Ao assinar a Carta da ONU, os Estados renunciaram não apenas a possibilidade do uso da força nas relações internacionais (ressalvada a legítima defesa), como concederam ao Conselho de Segurança a possibilidade final de decisão acerca do assunto.

Os Estados aderiram às Nações Unidas por meio de um processo formalmente voluntário, renunciando parte da sua soberania ao Conselho de Segurança. Observe-se que esse ato retirou do Estado a possibilidade de qualquer eventual reclamação em um caso concreto, cabendo à ONU a tomada de decisões acerca do uso da força.

Apesar dessa constatação de ordem factual, que remonta à década de 40 do século XX, a questão da soberania continua a ser invocada pelos Estados quando esses acreditam que estão sofrendo qualquer tipo de ingerência externa ou simplesmente quando não pretendem cumprir com certa normativa internacional.

O conceito de soberania surge conjuntamente com a fase inicial do Direito Internacional Contemporâneo, sob o marco temporal dos Tratados de Paz da Vestfália. Nesse primeiro momento, soberania era o "poder supremo que não reconhece outra acima de si" (ALMEIDA, 2013, p.4).

Sob a perspectiva do Direito Internacional, a soberania significava então que não haveria a primazia de um Estado sobre o outro, em um fundamento teórico para o princípio da igualdade soberana entre as nações, positivada na Carta da ONU, em seu artigo 1.

Pelo viés do Direito Interno, a soberania, no Estado Absolutista, consistia no poder ilimitado dos monarcas, o que, eventualmente, acabou por ser limitado pela própria lei. No

\footnotetext{
${ }^{8}$ Dispõe os artigos 2.3, 2.4 e o capítulo VII da Carta das Nações Unidas.
} 
Direito Internacional, onde a premissa era diferente, eventuais restrições à soberania também podem ser identificadas, como o exemplo citado do Conselho de Segurança das Nações Unidas.

Nesse contexto, Guilherme de Almeida, a partir dos ensinamentos de John H. Jackson propõe uma releitura do conceito de soberania, apresentando uma proposta de soberania moderna, ainda baseada no poder de decisão, mas que garanta o funcionamento de um instrumento jurídico de divisão do poder entre os diversos agentes da ordem internacional e nacional: Estados, Organizações Internacionais, Organizações não governamentais, Povos, Comunidades (2013, p.7).

De fato, pode ser creditado ao Direito Internacional dos Direitos Humanos parte da responsabilidade pela relativização do conceito de soberania. A noção de soberania dos Estados princípio fundamental do Direito Internacional teve iniciada a sua erosão com o aparecimento do Direito Internacional dos Direitos Humanos que lançou o indivíduo a condição de sujeito de direito na comunidade internacional.

Ainda que demonstrada a mudança no conceito clássico de soberania já tenha tido reflexos imediatos no Direito Internacional, como exemplificado acima (indivíduo como sujeito de Direito no plano internacional), a noção de limitação da soberania estatal, a partir de um ato inicialmente voluntário por parte do Estado, será objeto central em relação ao Direito Internacional dos Direitos Humanos, onde seu reflexo já é mais concreto.

O surgimento dos sistemas internacionais de proteção dos Direitos Humanos, assim como a eventual adesão dos Estados nacionais a esses instrumentos de defesa dos Direitos Humanos implicaram na renúncia voluntária de parte da soberania estatal em favor de convenções e organizações internacionais.

Esse tipo de adesão passou a ser uma tendência, especialmente após o fim da segunda Guerra Mundial. Conforme prediz Jack Donnelly, o mecanismo encontrado para tentar evitar a ocorrência de novos desastres semelhantes à Guerra Total seria por meio da proteção efetiva dos Direitos Humanos no plano internacional, o que explicaria a disposição estatal em renunciar parte de sua soberania (2003).

Contudo, as outras áreas do Direito Internacional não obtiveram adoção similar por parte dos Estados, apesar da existência da Corte Internacional de Justiça, em um processo que pode indicar a preferência pela adoção de instâncias judiciais internacionais para temas de Direitos Humanos, mas não de Direito Internacional como um todo.

De fato, identificar os motivos que fundamentam as razões para os Estados cada vez mais renunciarem parte de sua soberania é mais complexa. A evolução do Direito Internacional, a necessidade de legitimação política dos governos são fatores que contribuem para a questão. 


\section{A CORTE INTERNACIONAL DE JUSTIÇA}

A Corte Internacional de Justiça é um órgão principal da Organização das Nações Unidas, tendo sido oficialmente estabelecida em 1946, recebendo o seu primeiro caso em maio de 1947, a demanda referente ao Caso Canal de Corfu (Reino Unido V. Albânia).

Existem dois tipos de casos que podem ser propostos perante a Corte Internacional de Justiça: os casos contenciosos (contentious cases), e os pareceres consultivos (advisory proceedings).

Os casos contenciosos são aqueles em que se recorre ao Tribunal para resolver determinada controvérsia internacional. Apenas os Estados serão os legitimados a atuar como partes do processo nessa modalidade descrita, numa perspectiva tradicional que possui o Estado como o principal sujeito do Direito Internacional.

No caso dos pareceres consultivos, impera outra lógica, até pela natureza diversa em relação aos contenciosos. Esse tipo de procedimento está disponível apenas para os cinco órgãos das Nações Unidas e as dezesseis agências especializadas da mesma organização, além dos próprios Estados.

O início do Tribunal foi cercado de dúvidas e incertezas, representado pela falta de proposição de demandas perante a Corte Internacional de Justiça. A Assembleia Geral das Nações Unidas aprovou em 1947 a resolução 171 (II), que clamava por um uso mais efetivo da Corte.

Em um primeiro momento, a resolução surtiu efeito. Até o começo da década de 1960, a Corte recebeu em média de dois a três casos por ano, média similar à de sua predecessora, a Corte Permanente de Justiça Internacional. Contudo, a partir de 1962, a tendência inverteu-se, ocorrendo relutância dos Estados em acionar a jurisdição da Corte. De 1962 até 1971, apenas dois casos contenciosos (sendo que sobre a mesma matéria e propostos pelo mesmo autor) e um parecer consultivo foram apresentados à CIJ.

Diante desse quadro, o então Secretário Geral da ONU, U Thant, reiterou em seu relatório anual a importância da Corte Internacional de Justiça, o que culminou com a adoção de uma nova resolução pela Assembleia Geral (A/RES/3232) em 1974, que redefinia a importância e a atuação da Corte Internacional de Justiça.

A partir desse marco, a CIJ voltou a exercer um papel de protagonismo no cenário mundial, especialmente com o fim da Guerra Fria, implicando um aumento substancial no 
número de casos. Baseado nesse otimismo, a Assembleia Geral das Nações Unidas votou a resolução 44/23 de 1989, declarando o decênio que se iniciava em 1990 como a década do Direito Internacional das Nações Unidas. A resolução dizia que dever-se-ia promover os meios e métodos para a solução pacífica de controvérsias entre os Estados, inclusive recorrendo-se e apoiando-se integralmente a Corte Internacional de Justiça.

A conclusão desse período, nas palavras do relatório especial (A/54/362) elaborado pelo Secretário Geral da ONU, Kofi Annan, apontava que havia sido atingido notável sucesso no período programado, que os Estados estavam, cada vez mais, recorrendo à Corte.

Na primeira década do século XXI, a posição da Corte manteve-se inalterada, apesar de ofuscada pelo ativismo das Cortes Regionais de Direitos Humanos e pela consolidação do Tribunal Penal Internacional. Contudo, sua relevância mantém-se presente, apesar da problemática acerca da jurisdição, que costuma a ser um dos principais obstáculos à Corte.

\subsection{A QUESTÃO DA JURISDIÇÃO}

A jurisdição da Corte Internacional de Justiça é baseada no consentimento, ainda que ela seja um órgão da ONU. É pacífico o entendimento de que a CIJ só poderá exercer os limites da sua função jurisdicional sobre os Estados que assim o consentirem. Portanto, para demandar junto à Corte Internacional de Justiça, é preciso que o Estado preencha a condição de reconhecer o Estatuto do Tribunal.

Todos os membros das Nações Unidas são automaticamente partes integrantes do Estatuto, ou então, nos casos dos Estados que não sejam membros da ONU, precisam aceitar o artigo 93 (2) da Carta de São Francisco. Há ainda uma exceção para os Estados que venham a aceitar a recomendação do Conselho de Segurança, baseado no artigo 35 (2) do Estatuto ${ }^{10}$.

O Estado que preencher uma dessas hipóteses, deverá emitir um ato independente de consentimento, ainda que dentro de uma disputa em curso. Existem maneiras diferentes de se proceder com essa fase.

\footnotetext{
9 Segundo o artigo 93(2) da Carta: “Um Estado que não for Membro das Nações Unidas poderá tornar-se parte no Estatuto da Corte Internacional de Justiça, em condições que serão determinadas, em cada caso, pela Assembleia Geral, mediante recomendação do Conselho de Segurança”.

10 Segundo o artigo 35(2) do Estatuto: "As condições sob a s quais estará aberta a outros Estados serão fixadas pelo Conselho se Segurança com sujeição às disposições especiais dos tratados vigentes, mas tais condições não poderão de forma alguma colocar as partes em situação de desigualdade diante da Corte".
}

A primeira, baseada no artigo $36(1)$ do Estatuto $^{11}$, é conhecida como jurisdição 
voluntária. Nesse caso, os Estados emitem um consentimento ad hoc, reconhecendo a jurisdição da Corte para aquela demanda específica, nos limites acordados entre as partes. Esse procedimento é conhecido no Tribunal por special agreement ou compromis.

A segunda possibilidade envolve a capacidade do Estado em aceitar a jurisdição da Corte por acatar uma recomendação do Conselho de Segurança da ONU, previsto nos artigos 33 e 36 da Carta. Exemplo desse método é justamente o primeiro caso apresentado à Corte de Haia (Caso do Canal de Corfu), em que a Albânia submeteu a demanda ao Tribunal contra o Reino Unido por recomendação do Conselho de Segurança.

Por terceiro, os Estados podem demonstrar seu consentimento unilateralmente, explicitamente ou implicitamente (forum prorrogatum), inclusive mediante cláusula em tratado internacional. Justamente nessa terceira modalidade encontram-se os maiores desdobramentos.

Nesse sentindo, é possível ainda a aceitação genérica da jurisdição da Corte, que vinculará o Estado a ser parte em qualquer caso em que for demandado, ainda que proposta a ação unilateralmente (desde que a outra parte também reconheça essa condição). É a chamada jurisdição compulsória.

As discussões que envolvem a existência de uma jurisdição compulsória ocorrem desde a elaboração do Estatuto da Corte Permanente de Justiça Internacional. A época, escreveu-se um rascunho do documento que previa a compulsoriedade como obrigatória aos Estados nas questões legais. A redação acabou sendo alterada no texto final.

$\mathrm{O}$ assunto voltou à tona na elaboração do Estatuto da Corte Internacional de Justiça. Uma primeira corrente sustentava que a Corte deveria ser obrigatória para todas as disputas legais. Uma segunda opinião, defendia que os Estados que desejassem, poderiam posteriormente adotar a jurisdição compulsória unilateralmente. Essa segunda corrente foi a base do artigo 36 (2) do Estatuto. ${ }^{12}$

Contudo, após 64 anos de existência, apenas 66 países reconhecem a jurisdição compulsória da Corte, e ainda assim, na sua maioria com reservas. Desse número, encontra-se apenas um membro permanente do Conselho de Segurança (Reino Unido) e constata-se a ausência de relevantes atores internacionais, inclusive o Brasil.

11 Segundo o artigo 36(1) do Estatuto: "A competência da Corte se estende a todos os litígios que as partes a submetam e a todos os assuntos especialmente previstos na Carta das Nações Unidas ou nos tratados e convenções vigentes".

12 Segundo o artigo 36(2) do Estatuto: "Os Estados partes neste presente Estatuto que aceite a mesma obrigação, a jurisdição da Corte em todas as controvérsias de ordem jurídica que tratem sobre:" 
Um artigo do professor americano Eric Posner expõe números sobre a dinâmica da aceitação da jurisdição compulsória. Ele aponta que a maioria dos países do Conselho de Segurança denunciou a cláusula facultativa que aceitava a jurisdição obrigatória (caso dos Estados Unidos em 1986); apenas 13 dos 30 países com maior produto interno bruto adotaram a cláusula do 36 (2); em 1950, 60\% dos Estados reconheciam a jurisdição compulsória, atualmente o número caiu para 34\%; e a quantidade de tratados que preveem a Corte como jurisdição obrigatória tem tido sua média decrescida ano a ano (2006, p.131).

O doutrinador americano utiliza-se das estatísticas do Relatório da Corte Internacional de Justiça para apontar uma crise do Tribunal. Os números são importantes, mas omitem outros pontos de destaque. Apesar da debandada dos membros do Conselho de Segurança, movimento contrário pode ser percebido com a aceitação da jurisdição compulsória pelo Reino Unido em 2004; classificar a importância de um país por seu produto interno produto é extremamente economicista e demais simplista para o Direito Internacional; a quantidade de novos Estados soberanos mais do que duplicou de 1950 até 2010; e ainda, continuam a existir mais de 300 tratados em vigência que atribuem à CIJ jurisdição obrigatória(2005, p.5).

Nos últimos anos, poucos são os casos instituídos pelo compromis, sendo a maior parte realizada por meio da jurisdição compulsória, o que serviria para demonstrar a necessidade de fortalecimento desse instituto (LLAMZON; p.818).

Há quem não acredite na jurisdição obrigatória como instrumento eficaz da Corte Internacional de Justiça. É o caso do Juiz Oda, que, de maneira cética, defendia que a jurisdição compulsória resultaria em relutância do adimplemento da decisão pela parte demandada, implicando uma possibilidade real de descumprimento da sentença, acarretando a fragilização do poder e da credibilidade da Corte Internacional de Justiça.

Existem também outros doutrinadores do Direito e das Relações Internacionais que defendem posição contrária. Com o advento da década do Direito Internacional (década de 90), o então Secretário-Geral da ONU, Boutros Boutros-Ghali, descreveu a CIJ "como um recurso sub-aproveitado" e "que todos os Estados-membros deveriam reconhecer a jurisdição geral do artigo 36 do Estatuto, sem reservas"(ORGANIZAÇÃO DAS NAÇÕES UNIDAS, 1992, parágrafos 38 e 39$)$.

Posteriormente, o então Secretário-Geral da ONU Kofi Annan repetiu o apelo para que "todos os Estados que ainda não reconheceram, considerassem a jurisdição compulsória da Corte". Essa mesma mensagem foi reforçada no mesmo ano, na resolução 61/37 da Assembleia Geral das Nações Unidas, que no seu ponto 4, “convoca os Estados que ainda não o fizeram, a 
considerar a aceitação da jurisdição compulsória da Corte de acordo com o Estatuto"(ORGANIZAÇÃO DAS NAÇÕES UNIDAS, 2006).

A adesão em massa e sem restrições é praticamente utópica no cenário atual das relações internacionais. Contudo, avanços podem ser perquiridos e alguns já estão em progresso.

A Convenção de Viena sobre Direitos dos Tratados de 1969 consignou em seu artigo 66 o recurso à Corte Internacional de Justiça para solucionar controvérsias acerca a aplicação dos Tratados em geral, quando do surgimento de norma de jus cogens. Ainda que não seja uma hipótese aberta como a cláusula de jurisdição compulsória, ela possui uma abrangência significativa, considerando que envolve as fontes do Direito Internacional.

Não se deve confundir a jurisdição compulsória da Corte com a obrigatoriedade da sentença. Nesse ponto, são dois institutos jurídicos distintos. A jurisdição obrigatória é apenas o reconhecimento da CIJ como órgão legítimo para julgar as causas em que o Estado-parte for demandado, sem a necessidade de um novo ato de consentimento.

A jurisdição compulsória é uma realidade, devidamente respeitada e cumprida, ainda que dependente de um ato inicial voluntarista, mas ainda carente de um número mais expressivo de membros. Seu fortalecimento pode representar um grande desenvolvimento para o Direito Internacional com a consolidação da judicialização internacional.

A adoção da cláusula facultativa de jurisdição obrigatória é verdadeiro compromisso com a paz mundial e o respeito ao Direito Internacional. A própria Carta da ONU, em seu artigo 33(1), estabelece a solução judicial como um método de solução pacífica de controvérsia. Em uma realidade mundial assolada pela dificuldade de certas negociações e relacionamentos entre Estados, a imparcialidade de um Tribunal Internacional só teria a contribuir para desfazer desconfianças e resolver as demandas existentes segundo o Direito.

Em diversas áreas internacionais, nota-se essa crescente utilização de mecanismos jurisdicionais como fator complementar para resolver as questões mundiais. No âmbito do comércio, a Organização Mundial do Comércio possui sistema de resolução de controvérsias próprio. No âmbito dos Direitos Humanos, existem as Cortes Regionais e o próprio Tribunal Penal Internacional, que são exemplos do fortalecimento da judicialização de certas questões, sem que haja interferência para as soluções amistosas ou diplomáticas.

Não se propõe a judicialização para ofuscar os demais métodos de longa tradição histórica, mas a aplicação normativa do Direito (seja interno ou internacional) só está garantida mediante o controle juidicial efetivo. 


\subsection{A POSIÇÃO BRASILEIRA}

Como destaca Cançado Trindade, a cláusula facultativa da jurisdição obrigatória foi influenciada diretamente pelo diplomata e internacionalista brasileiro Raul Fernandes ${ }^{13}$. De fato, a participação do então Chanceler brasileiro nas discussões anteriormente referida da elaboração do Estatuto da Corte foi tão enérgica e notável que comumente a doutrina refere-se à cláusula como "Raul Fernandes".

O Brasil, como já dito, não adota a cláusula facultativa de jurisdição compulsória. De fato, o Estado brasileiro submeteu-se temporariamente à jurisdição obrigatória da Corte Internacional de Justiça, coadunando-se com a diretriz do Chanceler Raul Fernandes.

No entanto, a declaração de 12 de fevereiro de 1948 que reconhecia a cláusula facultativa e possuía prazo de dez anos jamais foi prorrogada ou revalidada. Não existe qualquer texto oficial que problematize ou racionalize as razões para tanto.

Pouco foi abordado pela doutrina a esse respeito. Em geral, atribui-se isso a uma tradição histórica brasileira de optar por soluções diplomáticas às suas controvérsias internacionais. Na opinião de Francisco Rezek:

[O Brasil] não voltou ao domínio da cláusula [Raul Fernandes] n[a] segunda fase da Corte [Internacional de Justiça], reafirmando seu velho gosto pelos meios diplomáticos de solução de conflitos internacionais, e pela arbitragem quando inevitável (1994, p.365).

Essa explicação é incompleta por atribuir a uma questão de opção de política interna a definição de um conteúdo que deveria possuir tratamento técnico. Por que o Brasil não adotou a cláusula "Raul Fernandes", se sua política externa sempre se pautou pela defesa da prevalência do Direito Internacional, da materialização da igualdade jurídica das nações na universal possibilidade de judicialização das controvérsias internacionais, do multilateralismo como fonte de legitimidade para a conformação normativa das relações internacionais?

Em 2009, ao ratificar a Convenção de Viena sobre Direito dos Tratados, o Brasil fez apenas duas reservas: sobre a aplicação provisória dos tratados e do reconhecimento da jurisdição da Corte Internacional de Justiça. Parece ser uma decisão equivocada não reconhecer o a jurisdição do Tribunal para esses casos, em uma decisão de contenção para priorizar a jurisdição interna, sob o argumento da tradição histórica brasileiras às soluções diplomáticas.

13 Raul Fernandes foi um político e diplomata brasileiro, Ministro das Relações Exteriores por duas vezes (19461951 e 1954-1955). 
É inegável o histórico brasileiro pela preferência às soluções negociadas, ante a arbitragem ou a judicialização das contendas. Defender esses dois elementos poderia constituir em grave contradição ao Estado Brasileiro. Embora certo de que a normatividade internacional não se materialize unicamente pelas jurisdições internacionais, é do mesmo modo funcionalmente indiscutível que a aplicação normativa apenas encontra concretude de direito mediante jurisdição, dado que as soluções negociadas operam na distinta racionalidade da equidade, o que poderia ser encarado como complementariedade, em vez de contradição.

Afirmar genericamente que o Brasil não reconhece a jurisdição da Corte é parcialmente incorreto. De fato, o Brasil ratificou em 1965 o Pacto de Bogotá de 1948 (Tratado Americano de Soluções Pacíficas), que em seu artigo 31, prevê:

\footnotetext{
De conformidade com o inciso $2^{\circ}$ do artigo $36^{\circ}$ do Estatuto da Corte Internacional de Justiça, as Altas Partes Contratantes declaram que reconhecem, com relação a qualquer outro Estado Americano, como obrigatória, ipso facto, sem necessidade de nenhum convênio especial, desde que esteja em vigor o presente Tratado, a jurisdição da citada Corte em todas as controvérsias de ordem jurídica que surjam entre elas e que versem sobre.
}

Por fim, a História do Brasil frente à experiência político-jurídica não abarcada pela citada declaração de 1948, nem pelo Pacto de Bogotá demonstra que o país jamais recusou a jurisdição da Corte, nem descumpriu ordem sua. Tampouco adotou postura evasiva quanto à aplicação do Direito Internacional por ela. Não houve qualquer controvérsia que o Brasil tenha deixado de resolver com sua contraparte de forma pacífica. Logo, embora não tenha adotado integralmente a cláusula Raul Fernandes, o Brasil jamais deixou de respeitar a importância da Corte Internacional de Justiça para o desenvolvimento do Direito Internacional, mas não a utiliza como meio preferencial para a solução das controvérsias.

\section{CONCLUSÃO}

O Direito Internacional dos Direitos Humanos apresenta uma mudança de paradigma em direção da objetivação do Direito Internacional, sob uma perspectiva de abandono do caráter voluntarista, da simples reciprocidade. Desse modo, passa a existir um fundamento que submete até mesmo os Estados, que seria a obrigação de respeitar os Direitos Humanos.

Parece possível constatar a existência de uma relação de influência essencialmente benéfica do Direito Internacional dos Direitos Humanos em um processo de transformação dos postulados e paradigmas do Direito Internacional. 
No entanto, esse processo é lento e gradual. O Direito Internacional em si continua com sua base assentadas no voluntarismo estatal, ainda que já existam indícios dessa mudança de paradigma, como ocorre com a aceitação internacional geral das normas de jus cogens.

O Direito Internacional, ainda que continue a depender do consentimento estatal, permanecerá sendo um dos principais meios de solução de controvérsias entre os Estados. A subutilização da judicialização internacional não representa necessariamente um medo ou aversão ao Direito Internacional, mas tão somente, em alguns casos, a atribuição de última ratio.

A Corte Internacional de Justiça contribui desde sua fundação ao receber casos importantes e decidir de forma técnica e precisa de forma a desenvolver o Direito Internacional. Se os Estados adotassem a cláusula de jurisdição obrigatória, não há dúvidas que isso representaria um avanço para o Direito. Todavia, ainda que sua jurisdição continue sendo utilizada apenas quando for aceita pelos Estados, a Corte continuará desempenhando sua função.

\section{REFERÊNCIAS}

ABILA. Committee, on Intergovernmental Settlement of Disputes. Reforming the United Nations: What About the International Court of Justice?. Chinese Journal of International Law 5: 39-65. Disponível em http://chinesejil.oxfordjournals.org/cgi/content/short/5/1/39

ALEXANDROV, Stanimir A. The Compulsory Jurisdiction of the International Court of Justice: How Compulsory Is It?. Chinese Journal of International Law Advance Access published on March 1, 2006, DOI 10.1093/chinesejil/jml008. Chinese Journal of International Law 5: 29-38. Acesso em: 15 fev. 2016

ALMEIDA, Guilherme Assis de. Do Direito Internacional Público rumo ao Direito Cosmopolita: O Direito Internacional dos Direitos Humanos (DIDH) como transição. São Paulo: USP, 2003.

\section{Soberania, Cosmopolitismo e Direito Internacional dos Direitos Humanos}

(DIDH). São Paulo: USP, $2004 . \quad$ Disponível em http://www.nevusp.org/downloads/down075.pdf. Acesso em: 12 fev. 2016.

BRANT, Leonardo Nemer Caldeira. A Corte Internacional de Justiça e a Construção do Direito Internacional. Belo Horizonte: Cedin, 2005.

BENTHAM, Jeremy. An Introduction to the Principles of Morals and Legislation. Oxford: Clarendon Press, 1996.

CORTE INTERNACIONAL DE JUSTIÇA. Increasing the Effectiveness of the International Court of Justice. Proceedings of the ICJ/UNITAR Colloquium to Celebrate the 
50thAnniversary of the Court, C. Peck and R. S. Lee (eds.), The Hague[etc.], 1997.

FRANCIONI, Francesco. International Soft Law: a contemporary assessment. In: Fifty Years of the International Court of Justice: Essays in Honour of Sir Robert Jennings. Cambridge: Cambrigde University Press, 2008.

HART, Herbert. O conceito de Direito. São Paulo: Martins Fontes, 2009.

LLAMZON, Aloysius P., Jurisdiction and Compliance in Recent Decisions of the International Court of Justice (November 2007). European Journal of International Law, Vol. 18, Issue 5, pp. 815-852, 2007. Disponível em: http://ssrn.com/abstract $=1148654$ or doi:10.1093/ejil/chm047. Acesso em: 02 fev. 2016

MORGENTHAU, Hans J. Política entre as Nações: a luta pelo poder e pela paz. São Paulo: IMESP, 2003.

ODA, Shiger. The Compulsory Jurisdiction of the International Court of Justice: A myth? International \& Comparative Law Quarterly, 49 , pp 251-277 doi:10.1017/S0020589300064150, 2000. Disponível em: http://journals.cambridge.org/action/displayAbstract?fromPage=online\&aid=1529684. Acesso em: 16 fev. 2016

ORGANIZAÇÃO DAS NAÇÕES UNIDAS. Estatuto da Corte Internacional de Justiça. São Francisco, 1945.

PAULSON, Colter. Compliance with Final Judgments of the International Court of Justice since 1987. The American Journal of International Law, Vol. 98, No. 3 (Jul., 2004), pp. 434-461. Disponível em http://www.jstor.org/stable/3181640. Acesso em: 05 fev. 2016

POSNER, Eric A., The Decline of the International Court of Justice (December 2004). U Chicago Law \& Economics, Olin Working Paper No. 233; U of Chicago, Public Law Working Paper No. 81. Disponível em: http://ssrn.com/abstract=629341 or doi:10.2139/ssrn.629341. Acesso em: 10 jan. 2016.

SCHULTE, Constanze. Compliance with Decisions of the International Court of Justice. New York:Oxford, 2004.

SEITENFUS, Ricardo. Manual das organizações internacionais. Porto Alegre: Livraria do Advogado, 1997.

SHAW, Malcolm N. International Law. 6. ed. Cambridge: Cambridge University Press, 2010.

TRINDADE, Antônio Augusto Cançado. O Direito Internacional em um Mundo em Transformação. Rio de Janeiro, São Paulo: Renovar, 2002. 